\title{
Pengembangan Desain Walker Fleksibel Bagi Lansia
}

\author{
Idiar $^{1)}$, Muhammad Yunus ${ }^{2)}$ \\ 1,2) Jurusan Teknik Mesin, Program Studi Teknik Perancangan Mekanik \\ Politeknik Manufakur Negeri Bangka Belitung \\ E-mail: idiaridiar9@gmail.com
}

\begin{abstract}
Abstrak
Kondisi kesehatan para lansia umumnya mengalami penurunan dimana hal tersebut dapat menyebabkan beberapa permasalahan fisik dan mental. Lansia yang berumur diatas 70 tahun atau 60 tahun yang memiliki kendala kesehatan dikategorikan lansia dengan resiko tinggi. Dalam melakukan aktivitas sehari-sehari didalam rumah ataupun diluar rumah seperti ke masjid, taman, dan lain-lain biasanya mereka menggunakan alat bantu jalan yang disebut walker. Jenis walker di pasaran masih terdapat keterbatasan sehingga perlu dikembangkan dalam satu rancangan walker yang fleksibel. Tahapan yang digunakan dalam penelitian pengembangan desain walker fleksibel yaitu penyusunan daftar kebutuhan, penentuan konsep referensi, pengembangan konsep alternatif, pemilihan konsep, dan analisa teknik dan postur terhadap desain yang terpilih.

Konsep yang terpilih memiliki spesifikasi yaitu tumpuan bagian depan berfungsi sebagai kaki tetap atau kaki beroda, lengan pemegang walker dapat diatur ketinggian naik-turun sebesar 150 mm, memiliki dudukan kursi yang dapat dilipat, dan walker dapat dilipat. Selain itu, hasil analisa tegangan pada komponen kritis yaitu poros tumpu utama didapatkan kriteria aman digunakan dimana nilai tegangan maksimum yang terjadi sebesar $7.35 \times 10^{6} \mathrm{~N} / \mathrm{m}^{2}$ diberikan masih dibawah nilai yield strength material kuningan $3.5 \times 10^{8} \mathrm{~N} / \mathrm{m}^{2}$. Analisa postur dengan metode RULA pada posisi berdiri dan duduk didapatkan rata-rata skor akhir sebesar 2 dengan kategori acceptable bagi pengguna walker.
\end{abstract}

Kata Kunci: lansia, resiko, desain, walker, fleksibel

Abstract

The health condition of the elderly generally has decreased which can cause several physical and mental problems. Elderly aged over 70 years or 60 years who have health problems are categorized as high risk elderly. In carrying out their daily activities inside the house or outside the house, such as going to the mosque, garden, etc., they usually use a equipment called a walker. The types of walkers on the market still have limitations, so they need to be developed in a flexible walker design. The stages used in the flexible walker design development research are compiling a list of requirements, determining reference concepts, developing alternative concepts, selecting concepts, and analyzing techniques and postures for the selected design.

The selected concept has specifications, namely the front pedestal functions as a fixed leg or wheeled leg, the arm of the walker holder can be adjusted up and down by $150 \mathrm{~mm}$ in height, has a seat that can be folded, and the walker can be folded. In addition, the results of stress analysis on the critical component, namely the main fulcrum, obtained safe criteria where the maximum stress value that occurs is $7.35 \times 10^{6}$ $\mathrm{N} / \mathrm{m}^{2}$ is given still below the yield strength value of the brass material $3.5 \times 10^{8} \mathrm{~N} / \mathrm{m}^{2}$. Posture analysis using the RULA method in standing and sitting positions obtained an average final score of 2 in the acceptable category for walker users.

Keywords: : elderly, risk, design, walker, flexible 


\section{PENDAHULUAN}

Lanjut usia (lansia) merupakan suatu kondisi dimana faktor kesehatan umumnya menurun yang dapat menyebabkan permasalahan secara fisik maupun mental. Hal tersebut disebabkan oleh keterbatasan dari fungsi organ tubuh manusia yang telah mengalami penuaan secara alami. Menurut Undang-Undang Nomor 13 Tahun 1998 definisi lanjut usia yaitu seorang manusia yang sudah mencapai usia lebih dari 60 tahun. Sedangkan kondisi lanjut usia yang lebih dari 70 tahun dan lanjut usia yang berumur 60 tahun atau lebih tetapi mempunyai masalah kesehatan termasuk dalam kategori yang memiliki resiko tinggi. Lanjut usia dengan kategori resiko tinggi dalam melakukan kegiatan sehari-hari seperti pergi ke toilet, masjid, atau taman memakai alat bantu yang disebut walker. Walker merupakan alat bantu berjalan yang terbuat dari material logam. Kerangka alat ini memiliki dua buah gagang yang dipakai oleh penggunanya sebagai pegangan tangan dan dilengkapi dengan empat buah kaki sebagai tumpuan [1].

Haryanto dalam penelitiannya, merancang walker dengan metode Value Engineering yang memakai roda dan rangka walker dibuat dari pipa berbahan besi dengan ukuran diameter $16 \mathrm{~mm}$ dan tebal $2 \mathrm{~mm}$. Desain walker ini menggunakan sistem slot yang berfungsi sebagai pengatur serta pegangan tangan dengan tekstur yang kasar untuk merangsang telapak tangan agar otot lengan bisa berkontraksi untuk penderita pasca stroke[2]. Selain itu, Alfadhlani, dkk. melakukan perbaikan desain alat bantu berjalan (kruk) bagi penderita cacat/cedera bagian kaki. Material yang dipilih adalah stainless steel dimana bahan ini dapat mengurangi berat kruk sebesar 28,6\%. Pegangan kruk didesain dengan derajat kemiringan yang dapat diatur dengan rasio penyesuaian sebesar $14,4^{\circ}$ yang bertujuan untuk mendapatkan kenyamanan pada tangan serta pergelangan tangan pada saat alat kruk ini digunakan oleh pengguna[3].

Umumnya di pasaran, ada tiga jenis walker yaitu standard-walker, frontwheeled walker dan four-wheeled walker. Adapun fungsi dari standard-walker dan front-wheel walker memiliki dua fungsi yang sama yaitu sistem pengatur ketinggian yang menggunakan pin yang dapat diatur pada jarak tertentu. Dua jenis walker ini juga dapat dilipat apabila sedang tidak digunakan oleh pengguna walker sehingga dapat mempermudah dalam hal penyimpanan alat. Berdasarkan hal tersebut 
diketahui bahwa jenis walker yang terdapat di pasaran tersebut masih terdapat keterbatasan fungsi sehingga perlu pengembangan rancangan satu jenis walker yang dapat berfungsi ganda dalam satu konstruksi walker baik sebagai standardwalker dan front-wheeled walker dengan mekanisme pengatur ketinggian yang fleksibel, serta memiliki sistem tempat duduk yang dapat dilipat. Selain itu, analisa kekuatan konstruksi walker dan postur dengan metode Rapid Upper Limb Assessment (RULA) menggunakan software design agar aman pada saat digunakan oleh lansia[4].

\section{METODE PENELITIAN}

Adapun tahapan yang digunakan dalam penelitian pengembangan rancangan walker yang fleksibel bagi lansia ini yaitu:

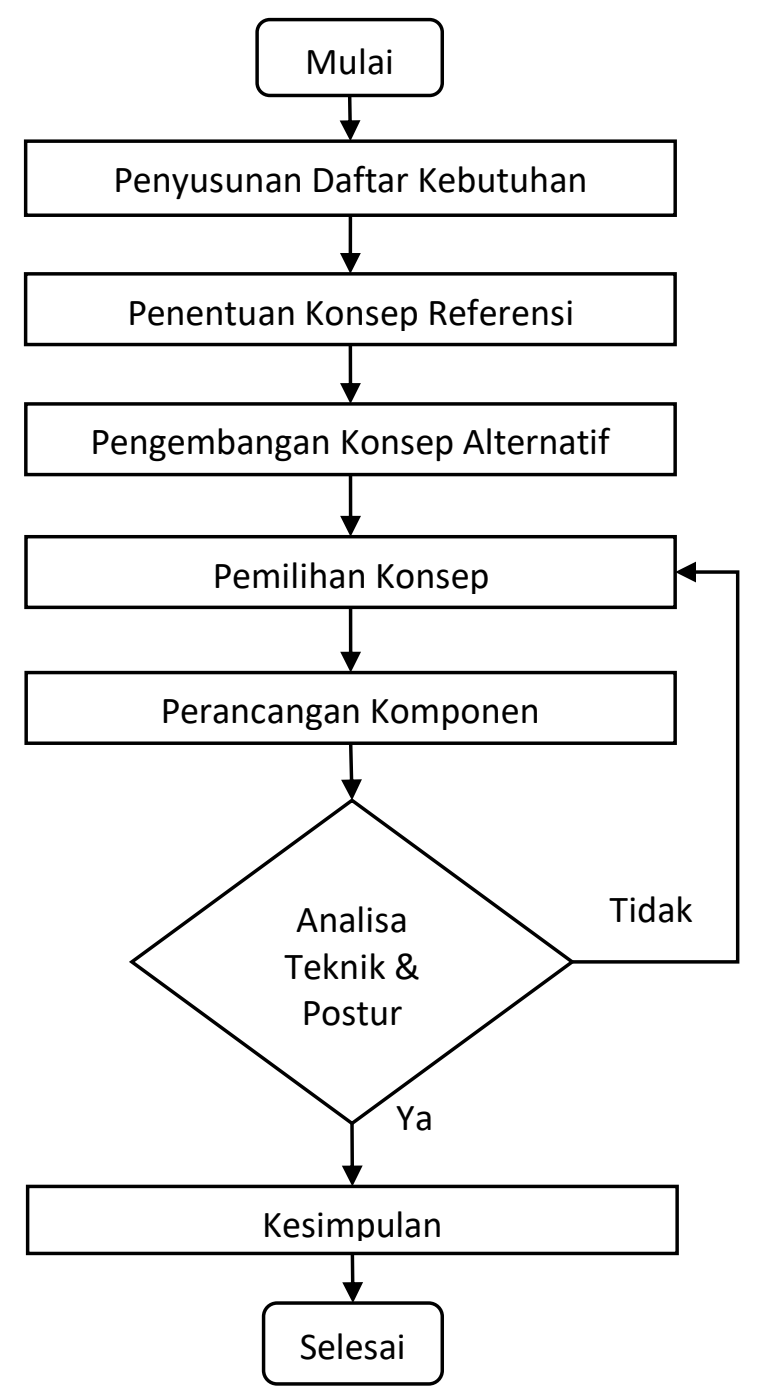

Gambar 1. Diagram Alir Penelitian 


\section{HASIL DAN PEMBAHASAN}

a. Daftar Kebutuhan

Langkah awal dalam pengembangan konsep adalah penyusunan daftar kebutuhan walker yang fleksibel. Tujuh kriteria utama dalam pengembangan produk ini yang terdapat dalam daftar kebutuhan dengan detail sebagai berikut [4]:

Tabel 1. Daftar Kebutuhan

\begin{tabular}{|c|c|c|}
\hline $\mathrm{S} / \mathrm{H}$ & $\begin{array}{c}\text { DAFTAR KEBUTUHAN PRODUK } \\
\text { Nama Produk “ Walker Fleksibel” } \\
\text { Uraian Kebutuhan }\end{array}$ & $\begin{array}{c}\text { Penanggung } \\
\text { Jawab }\end{array}$ \\
\hline $\begin{array}{l}\mathrm{S} \\
\mathrm{S} \\
\mathrm{S}\end{array}$ & $\begin{array}{l}\text { 1. Model (Fungsi): } \\
\square \text { Penumpu depan walker dapat diubah menjadi menjadi } \\
2 \text { jenis yaitu fixed atau beroda } \\
\square \text { Ketinggian gagang dapat diatur dengan jarak tertentu } \\
\square \text { Walker dapat dilipat } \\
\square \text { Walker dapat dijadikan tempat duduk }\end{array}$ & $\begin{array}{l}\text { Tim Desain } \\
\text { Dan } \\
\text { Manufaktur }\end{array}$ \\
\hline $\begin{array}{l}\mathrm{S} \\
\mathrm{S} \\
\mathrm{H}\end{array}$ & $\begin{array}{l}\text { 2. Kuat dan Aman: } \\
\square \text { Kuat menahan beban } 100 \mathrm{~kg} \\
\square \text { Aman digunakan oleh lansia } \\
\square \text { Konstruksi walker kokoh dan kuat }\end{array}$ & Tim Desain \\
\hline $\begin{array}{l}\mathrm{H} \\
\mathrm{H}\end{array}$ & $\begin{array}{l}\text { 3. Ergonomis: } \\
\square \text { Mudah digunakan oleh lansia } \\
\square \text { Resiko cedera tubuh pengguna kecil }\end{array}$ & Tim Desain \\
\hline $\begin{array}{l}\mathrm{H} \\
\mathrm{S}\end{array}$ & $\begin{array}{l}\text { 4. Berat: } \\
\square \text { Berat walker maksimal } 2.5 \mathrm{~kg} \\
\square \text { Mudah diangkat dan dipindahkan }\end{array}$ & Tim Desain \\
\hline $\begin{array}{l}\mathrm{H} \\
\mathrm{S}\end{array}$ & $\begin{array}{l}\text { 5. Pemeliharaan/Perawatan: } \\
\square \text { Mudah untuk dipelihara } \\
\square \text { Proses perawatan tidak sulit }\end{array}$ & $\begin{array}{l}\text { Tim Desain } \\
\text { Dan } \\
\text { Manufaktur }\end{array}$ \\
\hline $\begin{array}{l}S \\
S\end{array}$ & $\begin{array}{l}\text { 6. Manufaktur dan Perakitan: } \\
\square \text { Dapat dimanufaktur } \\
\square \text { Komponen pada konstruksi walker mudah dirakit dan } \\
\text { dilepas }\end{array}$ & $\begin{array}{c}\text { Tim } \\
\text { Manufaktur }\end{array}$ \\
\hline $\begin{array}{l}\mathrm{H} \\
\mathrm{H}\end{array}$ & $\begin{array}{l}\text { 7. Biaya Manufaktur: } \\
\square \text { Biaya produksi tidak tinggi } \\
\square \text { Harga terjangkau oleh masyarakat }\end{array}$ & $\begin{array}{l}\text { Seluruh } \\
\text { Tim }\end{array}$ \\
\hline
\end{tabular}

\section{b. Konsep Referensi}

Adapun jenis walker yang akan dikembangkan adalah jenis standard-walker dan front-wheeled walker. Kondisi kedua jenis walker di atas sebenarnya secara keseluruhan memiliki fungsi yang mirip dimana kedua konstruksinya dapat dilipat dan walker dapat diatur ketinggiannya, yang membedakan kedua adalah standardwalker tidak memiliki roda sedangkan front-wheeled walker memiliki roda pada bagian penumpu depan. Pada mekanisme pengatur ketinggian walker yang ada saat ini masih menggunakan pin yang dipasangkan terhadap lubang dengan jarak tertentu (misalnya: jarak antar lubang pin per $2.5 \mathrm{~cm}$ ), sehingga untuk mendapatkan 
dimensi ketinggian yang fleksibel agak mengalami kesulitan. Selain hal itu, pada kedua jenis walker diatas masih belum memiliki fungsi sebagai tempat duduk. Fungsi ini cukup penting bagi lansia pada saat capek setelah menggunakan walker maka dapat digunakan sebagai alternatif untuk tempat duduk. Dari penjelasan di atas dapat diketahui bahwa kedua jenis walker tersebut masih terdapat keterbatasan sebagai berikut:

- Fungsi standard-walker dan front-wheeled walker masih terdapat pada dua konstruksi yang berbeda.

- Pada mekanisme pengatur ketinggian kedua jenis walker tersebut kesulitan untuk mendapatkan dimensi pengaturan yang fleksibel.

- Belum terdapat fungsi yang dapat digunakan sebagai tempat duduk.

c. Konsep Alternatif

Ide pengembangan yang dilakukan berdasarkan keterbatasan-keterbatasan yang dimiliki oleh existing product seperti di atas adalah:

a) Menggabungkan kedua fungsi yang ada pada dua jenis walker ke dalam satu konstruksi walker.

b) Mekanisme pengatur ketinggian walker dibuat agar mendapatkan dimensi pengaturan yang fleksibel.

c) Menambahkan fungsi yang dapat digunakan sebagai tempat duduk.

d) Sistem konstruksi yang dapat dilipat.

Dalam pengembangan konsep rancangan ini ada 4 (empat) bagian utama yang menjadi perhatian yaitu:

1) Konstruksi roda yang dapat naik-turun pada penumpu depan,

2) Pengatur naik-turun gagang dengan setingan yang fleksibel.

3) Sistem tempat duduk yang dapat dilipat.

4) Konstruksi gagang yang dapat dilipat.

Berdasarkan daftar kebutuhan seperti yang tertera dalam tabel 3.1 maka dikembangkan 2 (dua) konsep rangka walker fleksibel dengan model diagram morfologi seperti yang terlihat pada gambar berikut: 
Tabel 2. Bagian-Bagian Utama Walker Fleksibel

\begin{tabular}{|l|c|}
\hline \multicolumn{1}{|c|}{$\begin{array}{c}\text { Bagian utama walker dengan } \\
\text { fungsinya }\end{array}$} \\
\hline $\begin{array}{l}\text { Konstruksi naik-turun roda pada } \\
\text { penumpu depan }\end{array}$ \\
\hline $\begin{array}{l}\text { Pengatur naik turun gagang dengan } \\
\text { setingan yang fleksibel } \\
\text { dilipat tempat duduk yang dapat }\end{array}$
\end{tabular}

\section{d. Pemilihan Konsep}

Setelah pengembangan 2 buah konsep sepeda dilakukan pemilihan konsep dengan model matrik keputusan, dengan tahapan penilaian konsep seperti pada tabel 3.2. Hal ini dilakukan karena hanya 3 konsep saja yang terpilih, sehingga tidak membutuhkan langkah penyaringan konsep. Kriteria seleksi ditetapkan dari daftar kebutuhan yang sudah ditetapkan sebelumnya.

Tabel 3. Matrik Evaluasi Konsep Walker Fleksibel

\begin{tabular}{|c|c|c|c|c|c|c|c|}
\hline \multirow{3}{*}{ Kriteria Seleksi } & \multirow{3}{*}{ Bobot } & \multicolumn{6}{|c|}{ Konsep } \\
\hline & & \multicolumn{2}{|c|}{ Konsep I } & \multicolumn{2}{|c|}{ Konsep II } & \multicolumn{2}{|c|}{ Referensi } \\
\hline & & Rate & $\begin{array}{c}\text { Skor } \\
\text { bobot }\end{array}$ & Rate & $\begin{array}{c}\text { Skor } \\
\text { bobot }\end{array}$ & Rate & $\begin{array}{c}\text { Skor } \\
\text { bobot }\end{array}$ \\
\hline 1. Multifungsi & $25 \%$ & 4 & 1 & 4 & 1 & 2 & 0,50 \\
\hline 2. Kuat dan aman & $15 \%$ & 3 & 0,45 & 3 & 0,45 & 3 & 0,45 \\
\hline 3. $\quad$ Ergonomis & $15 \%$ & 3 & 0,45 & 3 & 0,45 & 3 & 0,45 \\
\hline 4. $\quad$ Ringan & $15 \%$ & 3 & 0,45 & 4 & 0,6 & 3 & 0,45 \\
\hline 5. Mudah dirawat & $10 \%$ & 3 & 0,3 & 4 & 0,4 & 3 & 0,3 \\
\hline $\begin{array}{ll}\text { 6. } & \text { Mudah } \\
\text { dimanufaktur }\end{array}$ & $10 \%$ & 3 & 0,3 & 3 & 0,3 & 3 & 0,3 \\
\hline $\begin{array}{ll}\text { 7. } & \begin{array}{l}\text { Biaya } \\
\text { manufaktur }\end{array} \\
\end{array}$ & $10 \%$ & 3 & 0,3 & 3 & 0,3 & 3 & 0,3 \\
\hline & $\begin{array}{c}\text { Nilai } \\
\text { Absolut }\end{array}$ & & 3,25 & & 3,50 & & 2,75 \\
\hline & Nilai Relatif & & $32.5 \%$ & & $35 \%$ & & $27,5 \%$ \\
\hline
\end{tabular}


Berdasarkan evaluasi yang ditunjukkan oleh tabel diatas diketahui bahwa konsep II yang dipilih untuk dikembangkan, dimana konsep ini memiliki nilai absolut atau relatif yang paling besar yaitu 3.50 (35\% dari total nilai bobot). Adapun hasil rancangan untuk konsep II seperti gambar berikut ini:

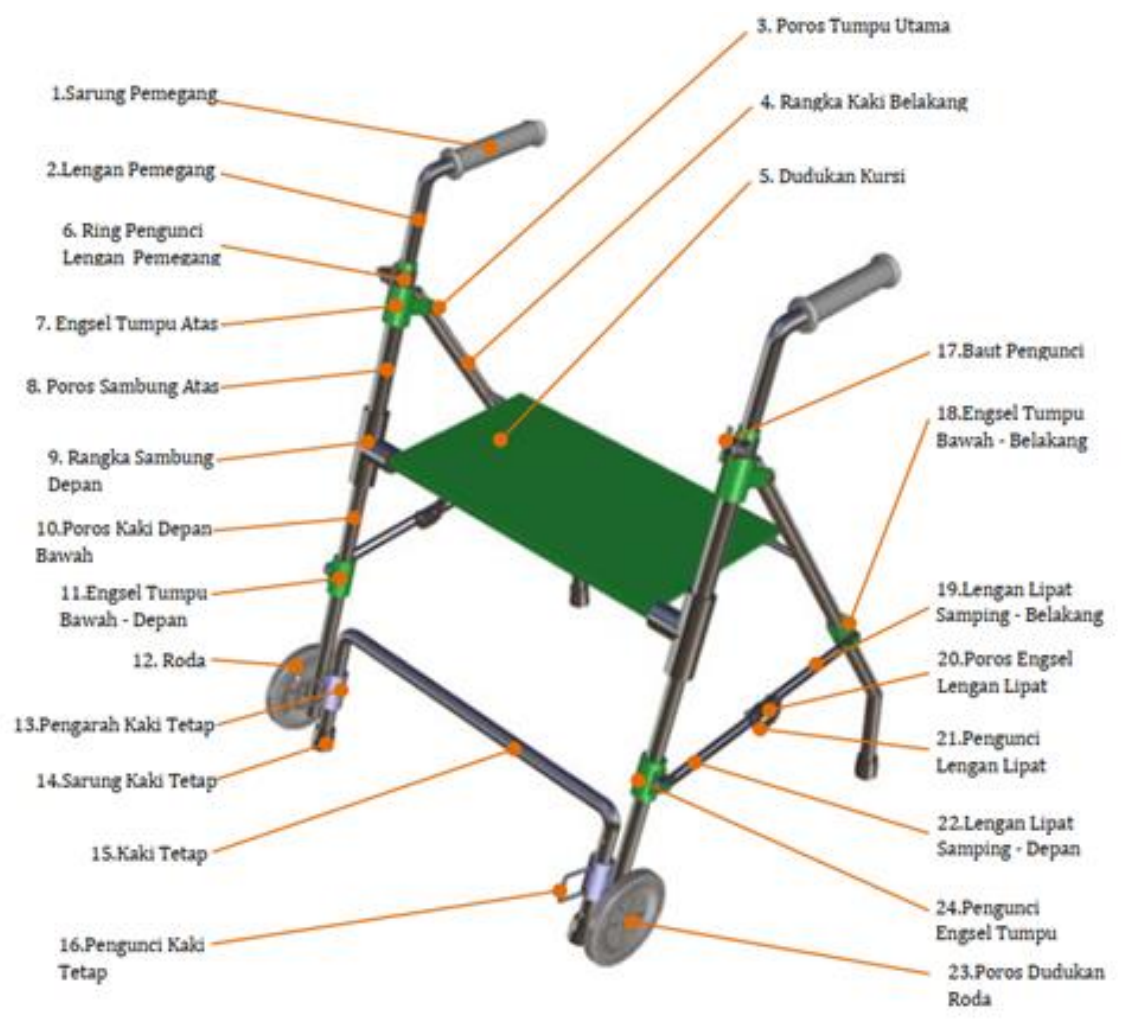

Gambar 2. Konsep Terpilih

Mekanisme kerja dari konstruksi walker fleksibel yang telah dirancang tersebut adalah sebagai berikut, yaitu:

- Tumpuan walker bagian depan dapat menggunakan 2 fungsi yaitu fungsi kaki tetap atau fungsi roda. Jika menggunakan Kaki Tetap, maka Kaki Tetap dapat digerakkan turun lalu dikunci oleh Pengunci Kaki Tetap. Sebaliknya, jika menggunakan Roda maka Kaki Tetap dapat dinaikkan keatas lalu dikunci.

- Lengan Pemegang dapat disetel naik-turun sejauh $150 \mathrm{~mm}$, jika ketinggian walker sudah sesuai dengan yang diinginkan maka lengan pemegang dapat dikunci dengan memutar Baut Pengunci untuk mengencangkan Ring Pengunci Lengan Pemegang.

- Pada saat walker tidak digunakan, maka Dudukan Kursi dapat dilipat atau bagian Dudukan Kursi dapat dilepas dari pengarahnya yaitu Rangka Kaki 
Belakang, setelah itu dilipat.

- Mekanisme pelipatan walker yaitu dengan cara melepaskan Pengunci Lengan Lipat, lalu Lengan Lipat Samping Belakang dan Lengan Lipat Samping Depan digerakkan kearah yang berlawanan. Hal tersebut agar konstruksi Rangka Kaki Belakang menempel ke konstruksi walker bagian depan. Pergerakan Rangka Kaki Belakang bertumpu pada Poros Tumpu Utama, sedangkan konstruksi walker bagian depan bertumpu pada Engsel Tumpu Atas.

e. Analisa Teknik

Komponen yang akan dianalisa tegangan hanya dilakukan pada komponen kritis. Analisa tegangan menggunakan software desain. Analisa menggunakan software ini diharapkan mampu mereduksi waktu analisa sehingga proses perancangan ini dapat lebih singkat. Hasil compute yang dilakukan pada komponen yang dominan mengalami tegangan yaitu sebagai berikut:
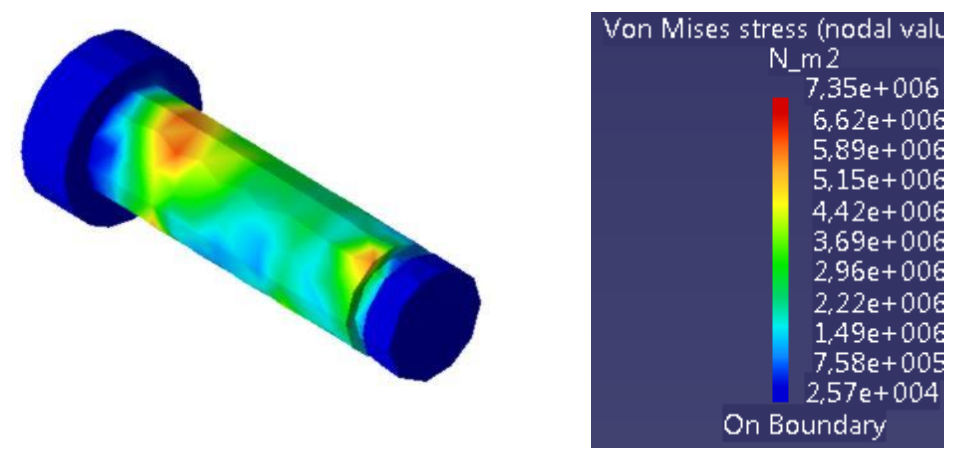

Gambar 3. Tegangan von misses komponen Poros Tumpu Utama

Nilai yield strength material kuningan sebesar $3,5 \times 10^{8} \mathrm{~N} / \mathrm{m}^{2}$. Bila dibandingkan dengan tegangan maksimum yang terjadi maka nilai tegangan maksimum lebih kecil dari yield strength. Hal tersebut menunjukkan bahwa material kuningan dengan dimensi komponen yang ada aman untuk digunakan. Setelah analisa tegangan pada komponen kritis selanjutnya dilakukan analisa postur yang berkaitan dengan pengunaan tubuh bagian atas dengan metode RULA dengan menggunakan software desain. Analisa dilakukan pada dua posisi yaitu pada saat pengguna berdiri dan pada saat duduk. Hasil analisa yang telah dilakukan adalah sebagai berikut: 

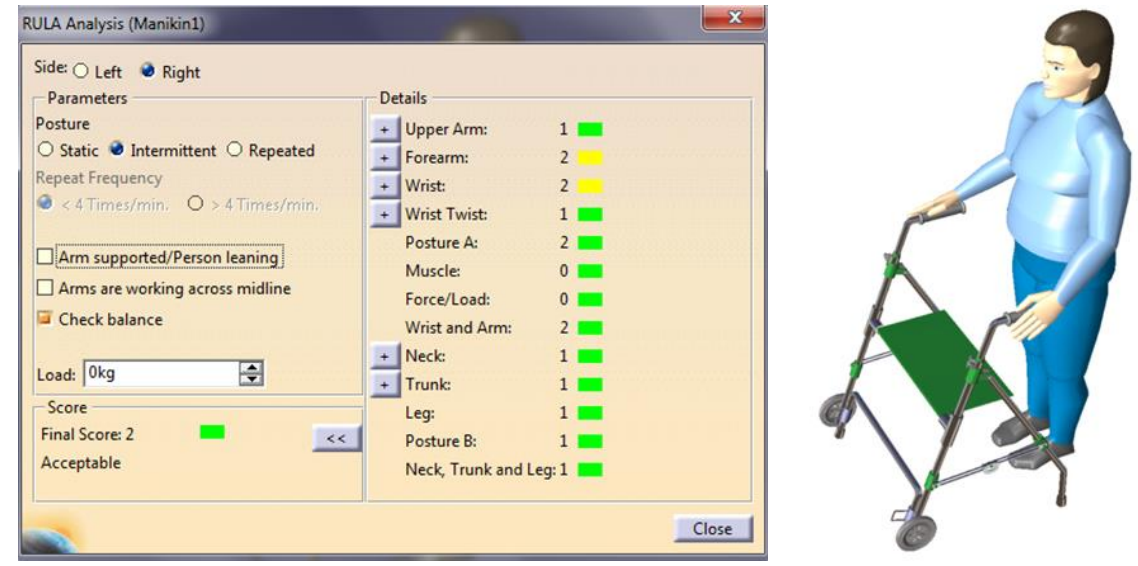

Gambar 4. Hasil analisa RULA untuk posisi berdiri
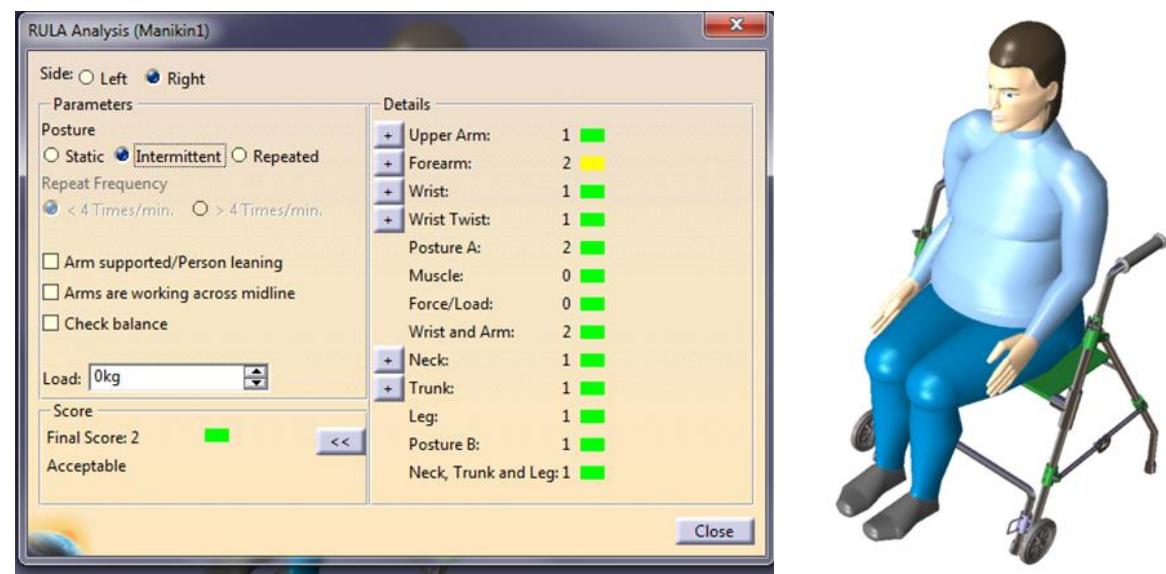

Gambar 5. Hasil analisa RULA untuk posisi duduk

Adapun hasil analisa RULA yang didapatkan untuk posisi berdiri dan posisi duduk saat penggunaan walker fleksibel yaitu acceptable bagi para pengguna sehingga aman saat beraktivitas dengan alat ini.

\section{KESIMPULAN}

Berdasarkan hasil penelitian pengembangan rancangan walker fleksibel ini didapatkan desain konsep walker fleksibel yang terpilih layak untuk dikembangkan lebih lanjut. Adapun konsep II terpilih memiliki spesifikasi yaitu tumpuan bagian depan berfungsi sebagai kaki tetap atau kaki beroda, lengan pemegang walker dapat diatur ketinggian naik-turun sebesar $150 \mathrm{~mm}$, memiliki dudukan kursi yang dapat dilipat, dan walker dapat dilipat.

Hasil analisa tegangan pada komponen kritis dari konstruksi walker 
fleksibel yaitu poros tumpu utama yang menggunakan material kuningan dengan ukuran yang telah ditetapkan aman untuk digunakan, hal tersebut dikarenakan nilai tegangan maksimum yang terjadi sebesar $7.35 \times 10^{6} \mathrm{~N} / \mathrm{m}^{2}$ diberikan masih dibawah nilai yield strength material kuningan $3.5 \times 10^{8} \mathrm{~N} / \mathrm{m}^{2}$. Analisa postur saat pengguna menggunakan walker fleksibel dalam posisi berdiri dan duduk dengan metode RULA menggunakan sofware desain didapatkan skor akhir sebesar 2 (dua) kategori acceptable dimana rancangan konstruksi walker fleksibel aman saat digunakan oleh pengguna.

\section{DAFTAR PUSTAKA}

[1] D. Djumhariyanto, "Pengembangan Alat Bantu Jalan (Walker) Dengan Metode Quality Function Deployment (QFD)," J. Flywheel., vol. 7, no. 1, pp. 35-44, 2016.

[2] L.T. Haryanto, "Perancangan Ulang Alat Bantu Jalan (Walker) Untuk Pasien Pasca Stroke Menggunakan Metode Value Engineering," Universitas Sebelas Maret Surakarta, 2012.

[3] Alfadhlani, Y. Meuthia, D. F. Valent, "Perbaikan Rancangan Kruk Ketiak Untuk Penderita Cedera Dan Cacat Kaki," J. Optimasi Sistem Industri., vol. 12, no. 2, pp. 400-410, 2013.

[4] I.M.L. Batan, Desain Produk, Jogjakarta: Andi Publisher, 2012. 